\title{
Stabilization of symptomatic carotid atherosclerotic plaques by statins: a clinico-pathological analysis
}

\author{
Takao Konishi $^{1,2} \cdot$ Naohiro Funayama $^{1} \cdot$ Tadashi Yamamoto $^{1} \cdot$ Daisuke Hotta $^{1} \cdot$ Ryota Nomura $^{3} \cdot$ Yusuke Nakagaki $^{3}$. \\ Takeo Murahashi ${ }^{3} \cdot$ Kenji Kamiyama $^{3} \cdot$ Tetsuyuki Yoshimoto $^{4} \cdot$ Takeshi Aoki $^{5} \cdot$ Shinya Tanaka $^{2}$
}

Received: 13 February 2018 / Accepted: 18 May 2018 / Published online: 22 May 2018

(c) The Author(s) 2018

\begin{abstract}
Human and animal studies have revealed a stabilization of atherosclerotic plaques by statins. However, the stabilization of human carotid plaques has not been thoroughly described pathologically. This analysis explored the relationship between statin therapy and plaque stability in carotid endarterectomy (CEA) specimens. We analyzed specimens harvested between May 2015 and February 2017, from 79 consecutive patients presenting with $>70 \%$ carotid artery stenoses, of whom 66 were untreated (group 1) and 13 treated (group 2) with a statin. Immunohistochemistry was performed, using an endothelial specific antibody to CD31, CD34 and platelet derived growth factor receptor- $\beta$. The prevalence of plaque ruptures $(P=0.009)$, lumen thrombi $(P=0.009)$, inflammatory cells $(P=0.008)$, intraplaque hemorrhages $(P=0.030)$ and intraplaque microvessels $(P<0.001)$ was significantly lower in group 2 than in group 1 . Among 66 patients presenting with strokes and infarct sizes $>1.0 \mathrm{~cm}^{3}$ on magnetic resonance imaging, the mean infarct volume was significantly smaller $(P=0.031)$ in group 2 $\left(4.2 \pm 2.5 \mathrm{~cm}^{3}\right)$ than in group $1\left(8.2 \pm 7.1 \mathrm{~cm}^{3}\right)$. The difference in mean concentration of low-density lipoprotein cholesterol between group $1(121 \pm 32 \mathrm{mg} / \mathrm{dl})$ and group $2(105 \pm 37 \mathrm{mg} / \mathrm{dl})$ was non-significant $(P=0.118)$. This analysis of plaques harvested from patients undergoing CEA suggests that statin therapy mitigates the plaque instability, which, in patients presenting with strokes, might decrease infarct volume.
\end{abstract}

Keywords Statin $\cdot$ Carotid artery disease $\cdot$ Carotid endarterectomy $\cdot$ Carotid plaque $\cdot$ Unstable plaque

\section{Introduction}

Electronic supplementary material The online version of this article (https://doi.org/10.1007/s00380-018-1193-6) contains supplementary material, which is available to authorized users.

Takao Konishi

takaokonishi0915@gmail.com

1 Department of Cardiology, Hokkaido Cardiovascular Hospital, 1-30, West 13, South 27, Chuou-ku, Sapporo 064-8622, Japan

2 Department of Cancer Pathology, Hokkaido University Graduate School of Medicine, Sapporo, Japan

3 Department of Neurosurgery, Nakamura Memorial Hospital, Sapporo, Japan

4 Department of Neurosurgery, Kashiwaba Neurosurgical Hospital, Sapporo, Japan

5 Department of Neurosurgery, Hokkaido Neurosurgical Memorial Hospital, Sapporo, Japan
Statins slow the progression of coronary atherosclerosis and lower the incidence of ischemic strokes [1]. Moreover, some studies have suggested that they lower total and ischemic cerebrovascular mortality, in secondary and primary prevention $[2,3]$. With the prescription of $80 \mathrm{mg}$ of atorvastatin daily, Amarenco et al. observed a 16\% reduction in the rate of fatal and non-fatal strokes and a $26 \%$ reduction in the rate of overall vascular events [2]. Therefore, the interest in the effects of statins on the morphology and functional characteristics of atherosclerotic carotid plaques in humans and animals, has been growing. In a pathological analysis of neointima and media of rabbit femoral arteries, an arterial infiltration by macrophages was abolished and the concentrations of monocyte chemoattractant protein-1 were significantly decreased by statin therapy [4]. In a mouse model, statins have decreased the retinal neovascularization [5]. However, pathological analyses of carotid atherosclerotic plaques in patients treated versus untreated with statins have 
not been directly compared. This study is a detailed pathological comparison of atherosclerotic lesions and plaque stability in patients who underwent carotid endarterectomy (CEA), previously treated versus untreated with a statin. In addition, in patients who had suffered a stroke, the infarct volume was measured by magnetic resonance (MR) imaging.

\section{Methods}

\section{Sample population}

We analyzed data collected in 71 men and 8 women $>30$ years of age who, between May 2015 and February 2017, underwent CEA consecutively in the departments of neurosurgery of Nakamura Memorial Hospital, Kashiwaba Neurosurgical Hospital or Hokkaido Neurosurgical Memorial Hospital, in Japan. The indication for surgery was the presence of a $>70 \%$, symptomatic carotid artery stenosis. Patients were classified as symptomatic if they had suffered an ischemic stroke or a transient ischemic attack within last 6 months. Carotid plaque modifications were observed within 3-12 months after the onset of statin therapy [6-10], 66 untreated patients were classified as group 1, and 13 patients treated with a statin for $\geq 6$ months were classified as group 2 . Two patients treated with a statin less than 6 months were excluded from this study. The mean age of group 1 was $73.8 \pm 7.0$ years and that of group 2 was $71.6 \pm 5.4$ years (ns). CEA specimens that had been severely damaged by their excision were excluded from this analysis.

This study, approved by the Ethics Committee of each participating medical institution, complies with the Declaration of Helsinki on ethical principles for medical research involving human subjects, and all patients granted their written, informed consent to participate.

\section{Histopathological examinations}

CEA was performed, using standard surgical techniques with minimal handling of the specimens. The plaques were removed en bloc, fixed in $10 \%$ buffered formalin, transected transversely in 5-mm specimens, and embedded in paraffin. After the 3- $\mu \mathrm{m}$ transverse sections from each block were stained with hematoxylin-eosin and elastica-Masson (which stains elastin black and collagen and proteoglycans green), the most stenotic segment and the proximal and distal adjacent segments were examined. The sections were examined by two independent observers, one of whom was an experienced histopathologist unaware of the clinical status and identity of the patients. The sections were immunohistochemically stained with anti-CD31, anti-CD34 and platelet derived growth factor receptor- $\beta$ antibodies, which recognize endothelial cells, to confirm the presence of microvessels in the plaque.

\section{Definitions of histopathological indices and semi-quantification of histopathological observations}

Plaque rupture is an area of disrupted fibrous cap, where the overlying thrombus is in continuity with the underlying necrotic core [11]. A thrombus consists of laminated platelets or fibrin, with or without interspersed red and white blood cells. Lipid core is defined as amorphous material containing cholesterol crystals [12]. An intraplaque hemorrhage is microscopically visible blood and thrombus inside the plaque. An intraplaque microvessel is a lumen surrounded by a rim of endothelial cells, highlighted by immunostaining with anti-CD34 antibodies. We also confirmed the presence of endothelial cells by immunostaining with anti-CD31 and platelet derived growth factor receptor- $\beta$ antibodies. Minimum fibrous cap thickness is the thinnest part of the fibrous cap among all the cross-sections of a plaque [12].

Using reproducible semi-quantitative scales, we classified and scored between 1 and 3 or 4, 10 microscopic, histological characteristics of unstable plaques (Table 1) [13-16]. The score of each plaque characteristics was calculated as the average of the three scores which were analyzed in the three consecutive sections in pathological images.

\section{Magnetic resonance imaging}

All patients presenting with strokes or transient ischemic attacks underwent T1, T2 and diffusion MR imaging, using a $1.5 \mathrm{~T}$ scanner. Images of 66 of the 79 symptomatic patients (55 in group 1 and 11 in group 2) were retrospectively reviewed and analyzed to identify the lesion location and infarct volume. Follow-up MR images were obtained 2-4 weeks after the onset of stroke. Supplemental Figure I shows the measurements of infarct volume by $\mathrm{T} 2$ images, as measured by computed tomography of intracerebral hemorrhage volumes [17], using the formula for an ellipsoid:

$(4 / 3 \pi(a / 2)(b / 2)(c / 2)$,

where $a, b$ and $c$ are the respective diameters in three dimensions.

\section{Statistical analysis}

Continuous variables are reported as means \pm standard deviations (SD) and categorical variables as counts and percentages. The normality of distributions was assessed by the Kolmogorov-Smirnov test. Between-group differences were examined, using Pearson's Chi square or Fisher's exact test for categorical variables and Student's 


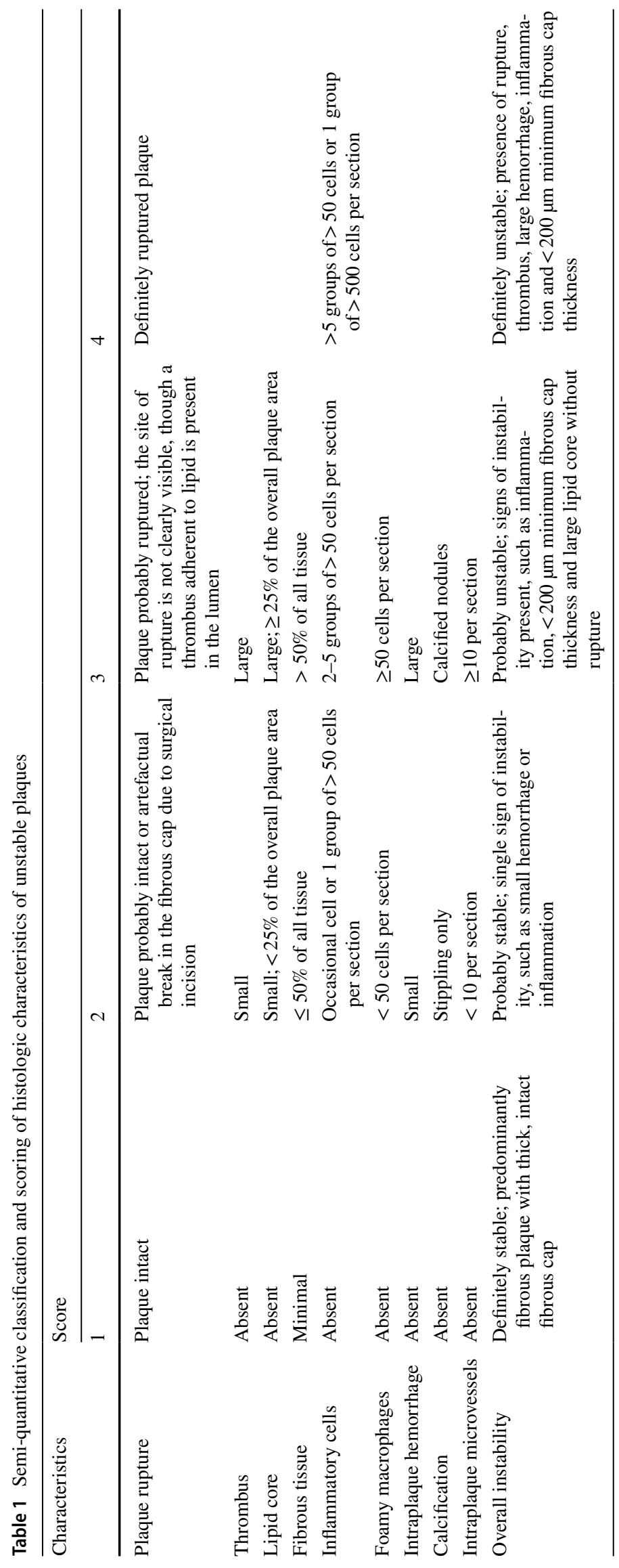


$t$ test or Mann-Whitney $U$ test for continuous variables, as appropriate. A $P$ value $<0.05$ was considered to indicate statistical significance. The data were analyzed with the SPSS 22.0 statistical system software (IBM Corporation, Armonk, NY, USA).

\section{Results}

\section{Clinical characteristics}

The clinical characteristics of the two groups of patients are compared in Table 2 . The prevalence of strokes was $83 \%$ in group 1 versus $85 \%$ in group $2(P=0.768)$. The mean concentration of low-density lipoprotein cholesterol was $121 \pm 32 \mathrm{mg} / \mathrm{dl}$ in group 1 versus $105 \pm 37 \mathrm{mg} / \mathrm{dl}$ in group $2(P=0.118)$. The other characteristics, including medications and concomitant diseases were likewise similar in both groups (Table 2). The doses and duration of the various statins administered in the 13 patients of group 2 are listed in Table 3.
Table 3 Individual doses of various statins and duration of therapy

\begin{tabular}{llrl}
\hline $\begin{array}{l}\text { Patient } \\
\text { number }\end{array}$ & Statin & $\mathrm{mg} /$ day & Duration of therapy \\
\hline 1 & Pitavastatin & 1.0 & $\geq 1$ year \\
2 & Rosuvastatin & 2.5 & $\geq 1$ year \\
3 & Rosuvastatin & 2.5 & 8 months \\
4 & Pravastatin & 10.0 & $\geq 1$ year \\
5 & Pitavastatin & 1.0 & $\geq 1$ year \\
6 & Rosuvastatin & 2.5 & 11 months \\
7 & Rosuvastatin & 2.5 & $\geq 1$ year \\
8 & Rosuvastatin & 2.5 & $\geq 1$ year \\
9 & Rosuvastatin & 2.5 & $\geq 1$ year \\
10 & Rosuvastatin & 2.5 & $\geq 1$ year \\
11 & Rosuvastatin & 10.0 & $\geq 1$ year \\
12 & Rosuvastatin & 2.5 & 6 months \\
13 & Atorvastatin & 5.0 & $\geq 1$ year \\
\hline
\end{tabular}

\section{Histopathological plaque characteristics}

The results of the semi-quantitative analysis of the various histopathological characteristics of the carotid plaques are compared in Table 4. Compared with group 1, the scores of plaque ruptures $(P=0.009)$, lumen thrombi $(P=0.009)$,
Table 2 Clinical characteristics of group 1 (statin-untreated) and group 2 (statin-treated)

\begin{tabular}{llll}
\hline & Group $1(n=66)$ & Group $2(n=13)$ & $P$ \\
\hline Age (years) & $73.8 \pm 7.0$ & $71.6 \pm 5.4$ & 0.213 \\
Men & $58(88)$ & $13(100)$ & 0.412 \\
Diabetes mellitus & $26(39)$ & $4(31)$ & 0.785 \\
Hypertension & $49(74)$ & $11(85)$ & 0.656 \\
Dyslipidemia & $53(80)$ & $13(100)$ & 0.180 \\
Chronic kidney disease & $17(26)$ & $3(23)$ & 0.884 \\
Current smoker & $19(29)$ & $7(54)$ & 0.151 \\
History of: & & & \\
Transient ischemic attack or cerebral infarction & $13(20)$ & $4(31)$ & 0.604 \\
Coronary artery disease & $9(14)$ & $3(23)$ & 0.657 \\
Peripheral artery disease & $3(5)$ & $1(8)$ & 0.636 \\
Prior drug therapy & & & 0.234 \\
Aspirin & $5(8)$ & $3(23)$ & 0.825 \\
Clopidogrel & $4(6)$ & $1(8)$ & 0.655 \\
Cilostazol & $1(2)$ & $0(0)$ & 0.384 \\
Days between stroke onset and carotid endarterectomy & $50 \pm 45$ & $39 \pm 33$ & \\
Baseline laboratory results & & & 0.904 \\
Glucose (mg/dl) & $135 \pm 50$ & $137 \pm 48$ & 0.118 \\
Cholesterol (mg/dl) & & & 0.934 \\
$\quad$ Low-density lipoprotein & $121 \pm 32$ & $105 \pm 37$ & 0.371 \\
$\quad$ High-density lipoprotein & $52 \pm 12$ & $2.2 \pm 1.1$ & \\
$\quad$ Low-density/high-density lipoprotein cholesterol & $2.5 \pm 0.9$ & $147 \pm 74$ & \\
Triglycerides (mg/dl) & & & \\
\hline Vales & & & \\
\hline
\end{tabular}

Values are mean \pm SD or numbers (\%) of observations 
Table 4 The scores of histological characteristics of group 1 (statinuntreated) and group 2 (statin-treated)

\begin{tabular}{lllr}
\hline & Group 1 $(n=66)$ & Group 2 $(n=13)$ & $P$ \\
\hline Plaque rupture & $2.82 \pm 0.77$ & $2.36 \pm 0.48$ & 0.009 \\
Lumen thrombus & $1.97 \pm 0.42$ & $1.69 \pm 0.32$ & 0.009 \\
Lipid core & $2.89 \pm 0.24$ & $2.79 \pm 0.32$ & 0.193 \\
Fibrous tissue & $2.38 \pm 0.36$ & $2.49 \pm 0.35$ & 0.319 \\
Inflammatory cells & $3.64 \pm 0.48$ & $3.31 \pm 0.48$ & 0.008 \\
Foamy macrophages & $2.84 \pm 0.29$ & $2.67 \pm 0.41$ & 0.088 \\
Intraplaque hemor- & $2.75 \pm 0.39$ & $2.49 \pm 0.46$ & 0.030 \\
$\quad$ rhage & & & \\
Calcifications & $2.43 \pm 0.62$ & $2.72 \pm 0.40$ & 0.113 \\
Intraplaque microves- & $2.88 \pm 0.23$ & $2.59 \pm 0.34$ & $<0.001$ \\
$\quad$ sels & & & \\
Overall instability & $3.29 \pm 0.38$ & $3.13 \pm 0.26$ & 0.098 \\
\hline
\end{tabular}

Values are mean $\pm \mathrm{SD}$ inflammatory cells $(P=0.008)$, intraplaque hemorrhages $(P=0.030)$ and intraplaque microvessels $(P<0.001)$ were significantly lower in group 2 . Furthermore, the mean number ( $26 \pm 18$ versus $51 \pm 32$ per section) and mean density $\left(1.06 \pm 0.84\right.$ versus $2.19 \pm 1.43$ per $\left.\mathrm{mm}^{2}\right)$ of intraplaque microvessels were significantly lower in group 2 than in group 1 ( $P<0.001$ for both comparisons). Representative examples of morphological differences between the two groups are shown in Figs. 1, 2, 3, 4 and 5.

Several correlations were observed among these plaque characteristics. Intraplaque hemorrhage $(r=0.489$; $P<0.001)$, lumen thrombus $(r=0.721 ; P<0.001)$ and inflammatory cells $(r=0.254, P=0.024)$ were positively correlated with plaque rupture (Fig. $6 a-c)$. Intraplaque hemorrhage was positively correlated with lumen thrombus $(r=0.460 ; P<0.001$; Fig. $6 \mathrm{~d})$ and inflammatory cells $(r=0.508 ; P<0.001 ;$ Fig. $6 \mathrm{e})$, and intraplaque microvessels

A

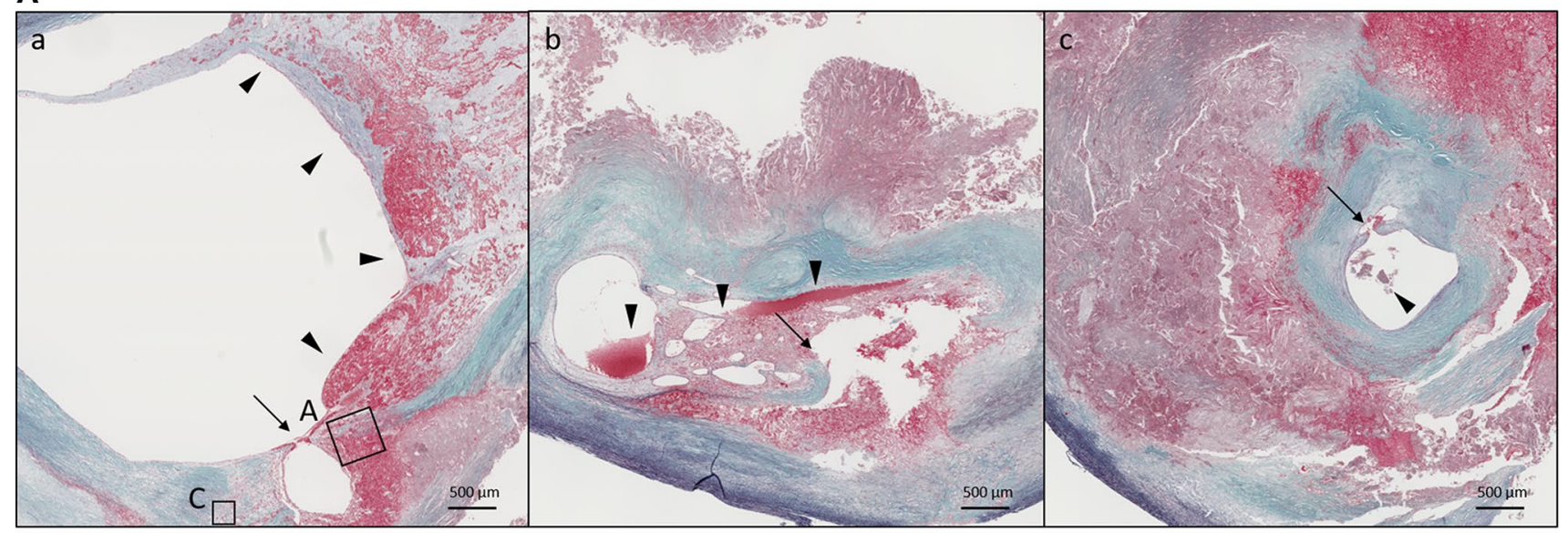

B

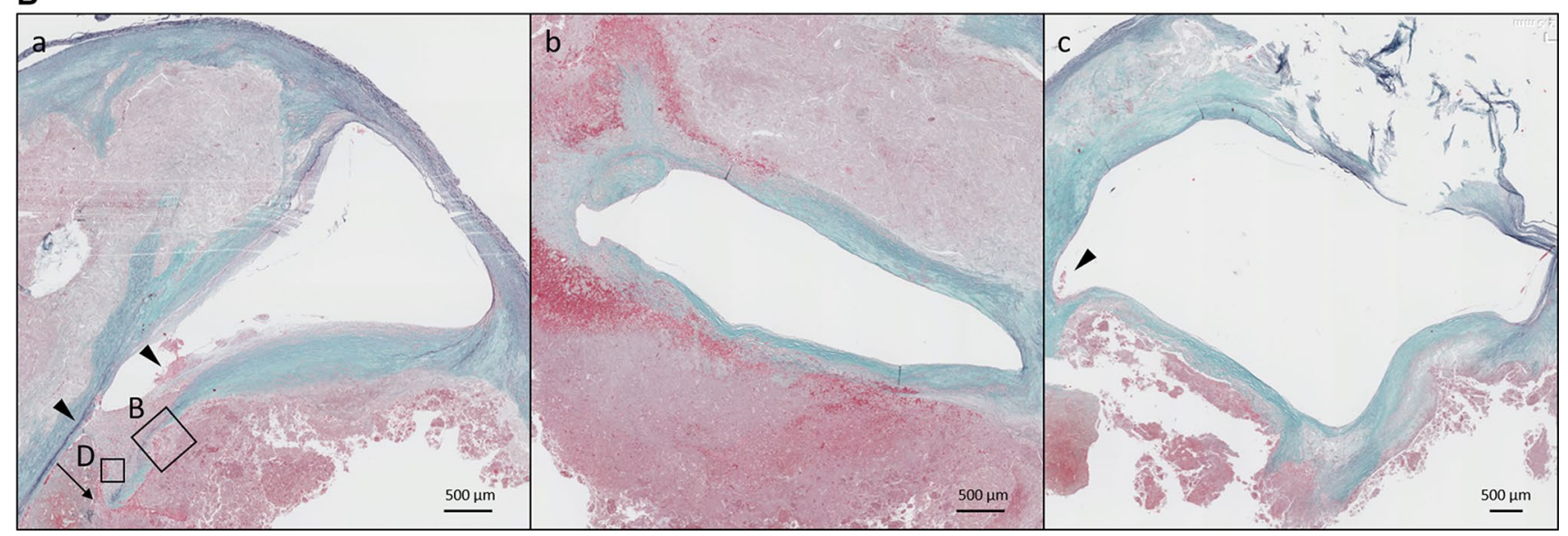

Fig. 1 Representative microscopic plaque characteristics (low power images). A Ruptured plaque (a-c thin arrows) with large (a, b arrowheads) and small (c arrowhead) luminal thrombi harvested from a patient untreated with a statin. An extensive intraplaque hemorrhage is visible in each section. The squared area is magnified in Fig. 2a, c. Elastica-Masson staining. B Ruptured plaque (a thin arrow) with a large (a arrowheads) and small (c arrowhead) luminal thrombus stained in elastica-Masson from a patient treated with statins. A widespread (b) and comparatively focal (a, c) intraplaque hemorrhage is visible. The squared area is magnified in Fig. 2b, d. Eastica-Masson staining 

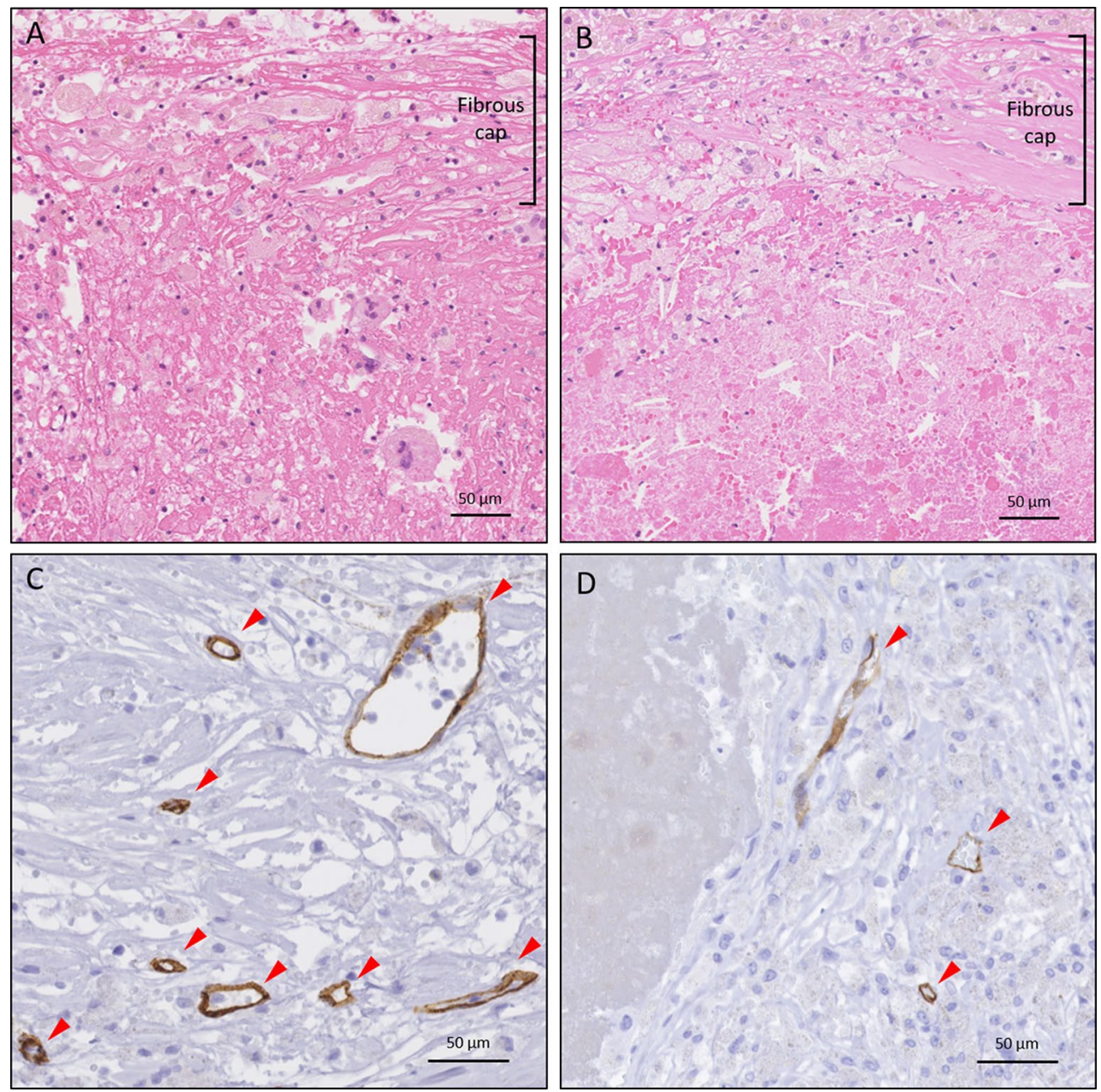

Fig. 2 Representative microscopic plaque characteristics (high power images). a, b More prominent infiltration of inflammatory cells in a than in b. Hematoxylin-eosin staining. c, d. More prominent CD34 staining of intraplaque microvessels (red arrowheads) in $\mathbf{c}$ than in $\mathbf{d}$

was positively correlated with inflammatory cells $(r=0.301$; $P=0.007$; Fig. 6f). There was no correlation between intraplaque hemorrhage and intraplaque microvessels $(r=0.088$; $P=0.442)$.

\section{Comparison of infarct volume in group 1 versus group 2}

On follow-up MR imaging the mean infarct volume in the 66 patients who suffered strokes was $3.5 \pm 5.5 \mathrm{~cm}^{3}$. In the subgroup whose infarct volume was $<1.0 \mathrm{~cm}^{3}$, the mean volume in group $2\left(0.25 \pm 0.24 \mathrm{~cm}^{3}\right)$ was smaller than in group $1\left(0.39 \pm 0.31 \mathrm{~cm}^{3}\right)$, though this difference was not statistically significant $(P=0.381 ;$ Fig. $7 \mathrm{a})$. In contrast, in the subgroup whose infarct volume was $\geq 1.0 \mathrm{~cm}^{3}$, the mean volume in group $2\left(4.2 \pm 2.5 \mathrm{~cm}^{3}\right)$ was significantly smaller than in group $1\left(8.2 \pm 7.1 \mathrm{~cm}^{3} ; P=0.031\right.$; Fig. 7b). Representative MR images from both groups are shown in Fig. 8 .
The mean time interval between onset of stroke and followup MR imaging was similar in both groups (data not shown).

\section{Correlation between infarct volume and histopathologic plaque characteristics in patients presenting with strokes}

In patients presenting with strokes, infarct volume was positively correlated with lumen thrombus (Table 5; Fig. 9). On the other hand, there was no correlation between infarct volume and the other histopathologic plaque characteristics (Table 5).

\section{Discussion}

The main observations made in this study were: (1) in patients treated with statins, plaque ruptures, lumen thrombi, intra-plaque hemorrhages, intraplaque microvessels and 


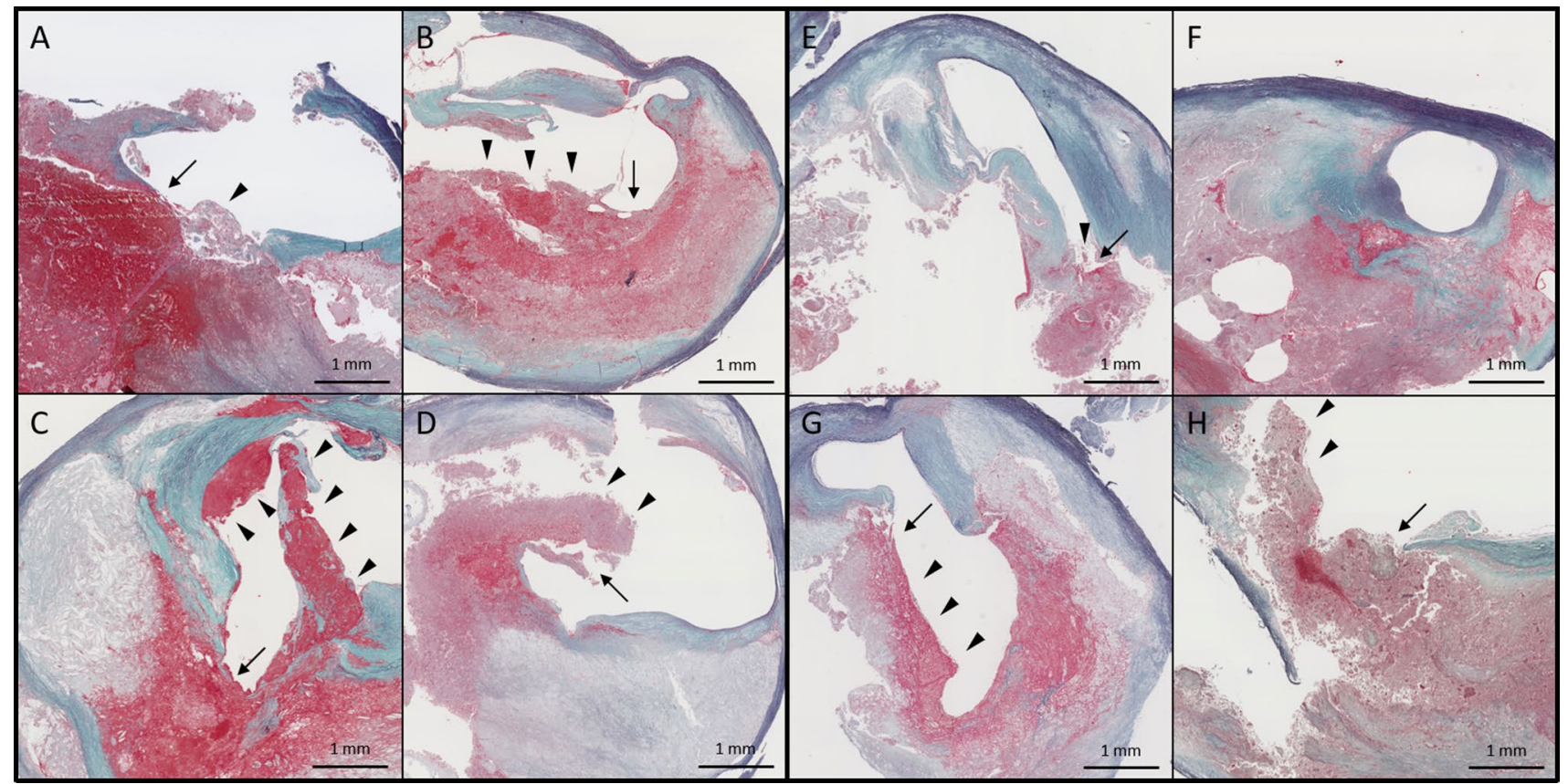

Fig. 3 Representative microscopic plaque characteristics (low power images). Ruptured plaque (a-e, $\mathbf{g}, \mathbf{h}$ thin arrows) with large (b-d, $\mathbf{g}$, $\mathbf{h}$ arrowheads) and small (a, e arrowhead) luminal thrombi harvested from a patient untreated $(\mathbf{a}-\mathbf{d})$ or treated $(\mathbf{e}-\mathbf{h})$ with a statin. The cases of a-d in Fig. 3 correspond to those of $\mathbf{a}-\mathbf{d}$ in Figs. 4 and 5, respectively

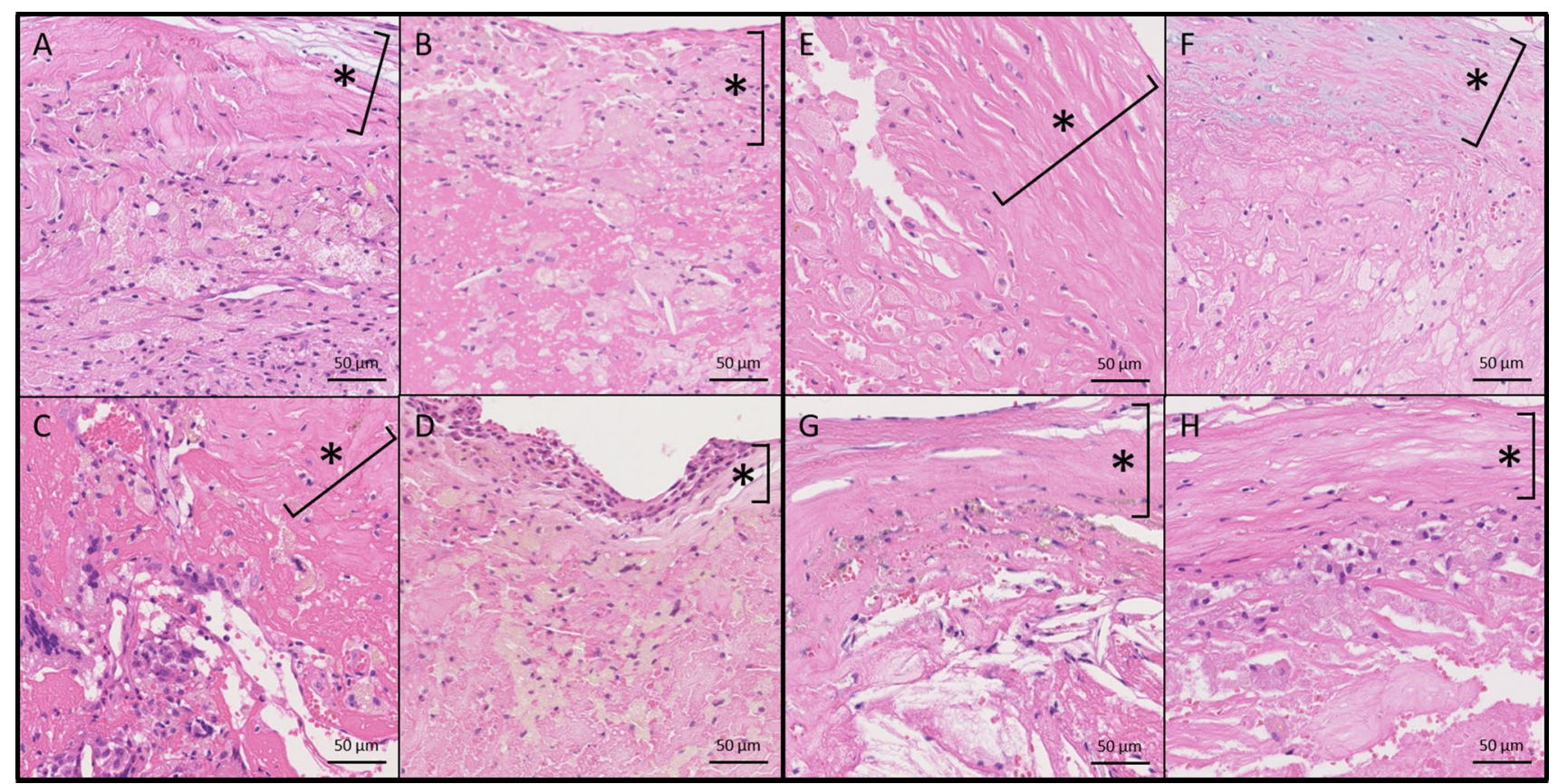

Fig. 4 Representative microscopic plaque characteristics (high power images). More prominent infiltration of inflammatory cells in a-d than in e-h. Hematoxylin-eosin staining. Each asterisk indicates fibrous cap

inflammatory cells were significantly less prevalent than in patients untreated with statins, while the mean concentration of low-density lipoprotein cholesterol was similar in both groups; and (2) in patients presenting with strokes whose infarct size was $>1.0 \mathrm{~cm}^{3}$ on MR imaging, the mean infarct volume was significantly smaller in the group treated than in the group untreated with statins. To the best of our knowledge, this clinico-pathologic study is the first (a) in depth 


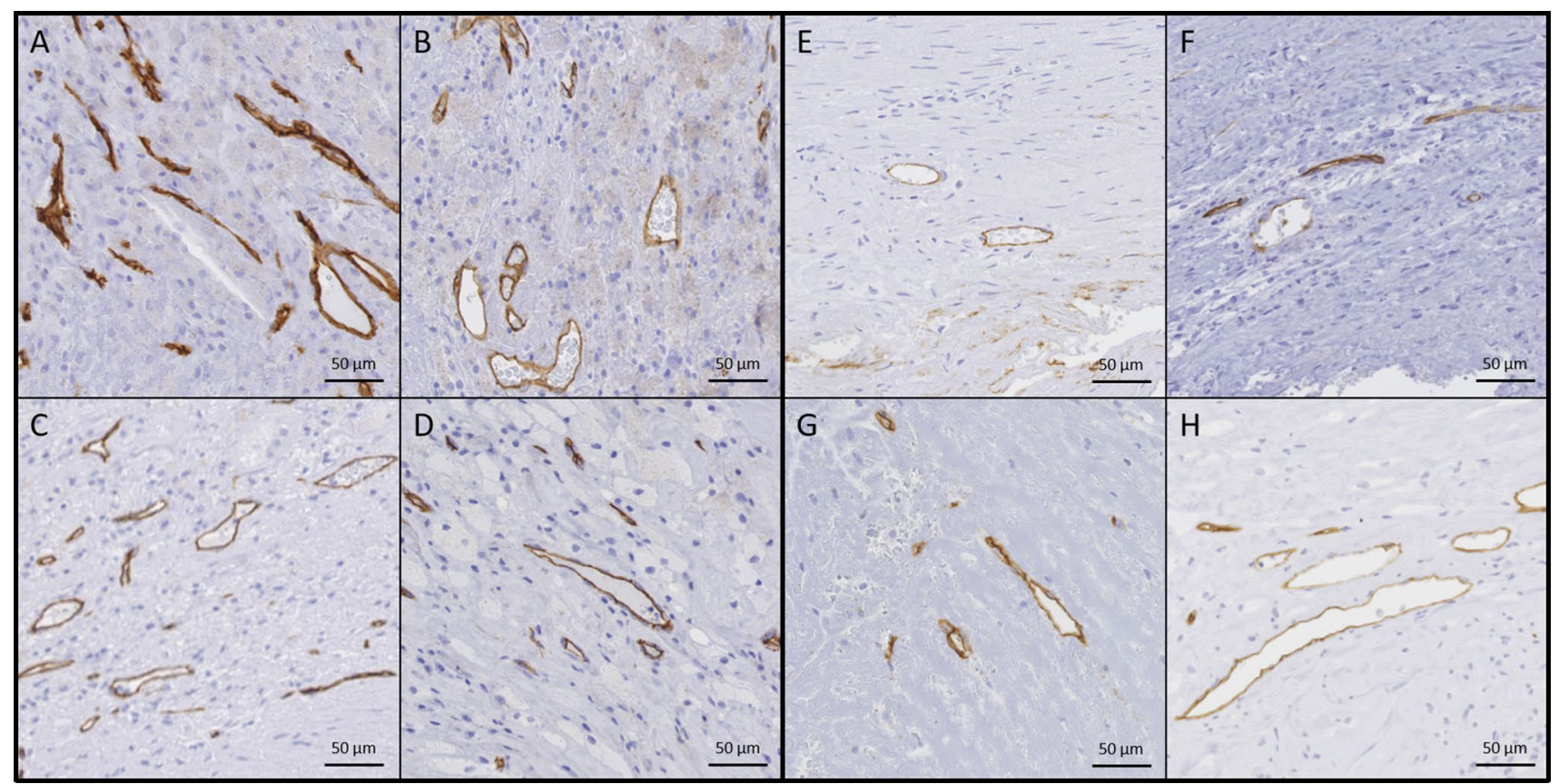

Fig. 5 Representative microscopic plaque characteristics (high power images). More prominent CD34 staining of intraplaque microvessels in a-d than in $\mathbf{e}-\mathbf{h}$

comparison of carotid artery plaques harvested from patients treated versus untreated with statins, and (b) analysis of the correlations among statin use, pathological characteristics and infarct volume in patients with strokes who underwent CEA. These observations further our understanding of the pathological characteristics of unstable plaques and of the pharmacological effects of statins on atherosclerotic plaques, which may have important implications with regard to the treatment of patients presenting with carotid artery stenoses.

\section{Statins, plaque rupture and intraplaque hemorrhage}

The significantly lower plaque rupture score in patients who had received prior statin therapy than in those who had not been treated, suggests that the treatment narrowed the range of plaque ruptures. Endothelial dysfunction is a cause of plaque progression and a trigger of plaque rupture [18, 19]. Statins mitigate endothelial dysfunction in coronary and peripheral arteries of patients with or without dyslipidemia [20-22], and increase the concentrations and activity of endothelial nitric oxide (NO) synthase in human endothelial cells [23, 24]. They also improve vascular function by decreasing the production of endothelin [25]. Because inflammatory cells, such as macrophages and T cells, produce metalloproteinases and cytokines that weaken the tensile strength of the collagen cap, resulting in plaque rupture, less inflammation in atherosclerotic plaques might also attenuate the magnitude of plaque rupture (Fig. 6c). These effects might limit the size of plaque ruptures in patients treated with statins.

The lower prevalence of intraplaque hemorrhages in patients treated than in patients untreated with statins can be explained by fewer plaque ruptures. Figure 6 a shows a positive correlation between intraplaque hemorrhages and plaque ruptures $[26,27]$. Fewer plaque ruptures in the statin group might translate into fewer intraplaque hemorrhages from less luminal discontinuity, thus less penetration of blood into the plaque.

There are at least three explanations for the positive correlation between intraplaque hemorrhage and inflammation. First, intraplaque hemorrhages introduce neutrophils and mononuclear cells into the plaque, and leukocyte extravasate from the intraplaque microvessels [28]. Second, erythrocytes included in the intraplaque hemorrhages rapidly release large amounts of hemoglobin, which attract inflammatory cells to the atherosclerotic plaque [29]. Third, the migration of macrophages may be promoted by multi-specific receptors on erythrocyte membranes, including monocyte chemoattractant protein-1 [30]. Michel et al. indeed, observed a high density of macrophages involved in red blood cells and iron phagocytosis in intraplaque hemorrhages [28]. These observations explain the positive correlation we found between intraplaque hemorrhage and inflammatory cells. 

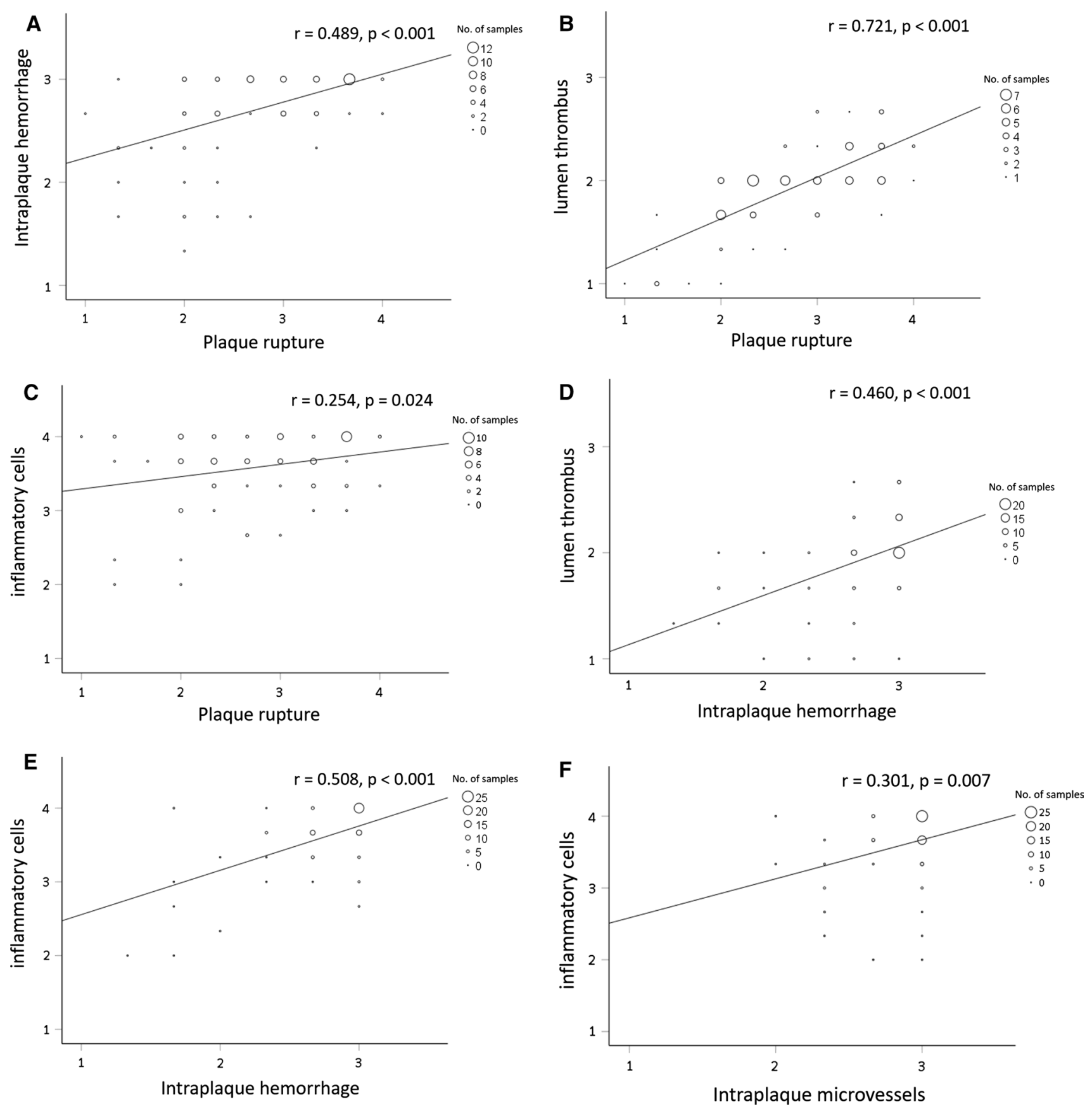

Fig. 6 The relationships between scores of the plaque characteristics. Correlations between a plaque rupture and intraplaque hemorrhage $\left(r=0.489, r^{2}=0.239, P<0.001\right)$, b plaque rupture and lumen thrombus $\left(r=0.721, r^{2}=0.520, P<0.001\right)$, $\mathbf{c}$ plaque rupture and inflammatory cells $\left(r=0.254, r^{2}=0.065, P=0.024\right), \mathbf{d}$ intraplaque hemorrhage

While immature and leaky intraplaque microvessels are a known source of intraplaque hemorrhage [31], intraplaque

and lumen thrombus $\left(r=0.460, r^{2}=0.212, P<0.001\right)$, e intraplaque hemorrhage and inflammatory cells $\left(r=0.508, r^{2}=0.258, P<0.001\right)$ and $\mathbf{f}$ intraplaque microvessels and inflammatory cells $(r=0.301$, $\left.r^{2}=0.090, P=0.007\right)$

hemorrhage in this study was probably due mostly to plaque rupture, since we found no correlation between intraplaque hemorrhage and intraplaque microvessels. 
Fig. 7 Comparison of infarct volume in patients presenting with strokes in group 1 versus group 2. Among patients presenting with strokes, whose infarct volume was $\geq 1.0 \mathrm{~cm}^{3}$, the mean infarct volume was significantly smaller $(P=0.031)$ in group 2 than in group 1

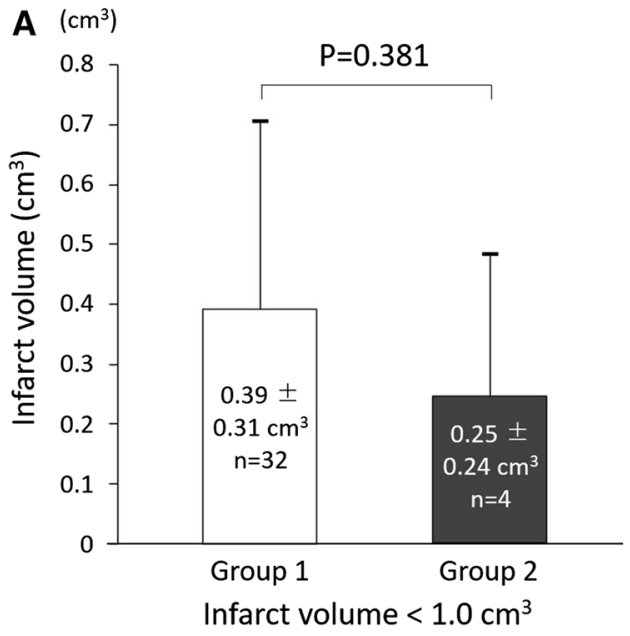

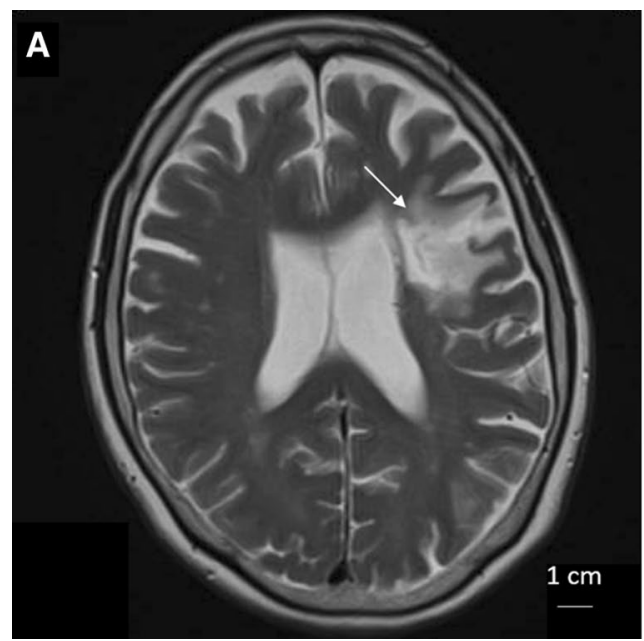

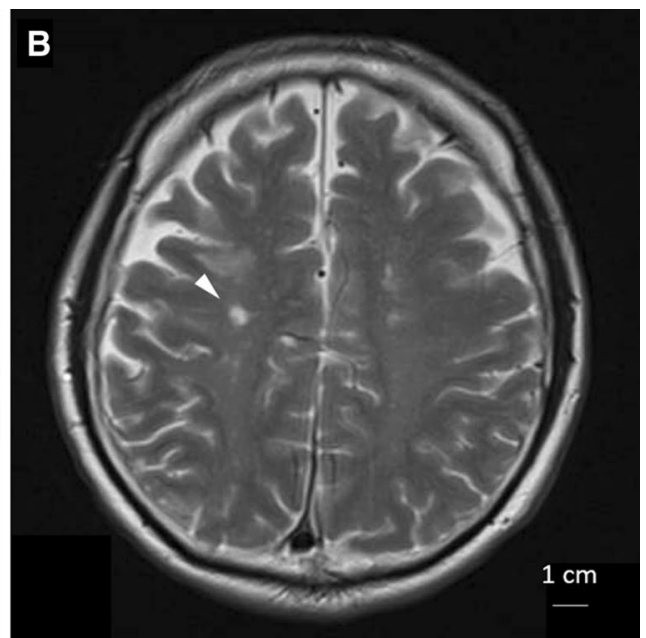

Fig. 8 Representative MR images of the statin and no-statin patients. The infarct volume was measured as a $13.8 \mathrm{~cm}^{3}$ in a 60 -year-old female without previous statin (arrow) and $\mathbf{b} 1.9 \mathrm{~cm}^{3}$ in a 69 -year-old male with previous statin (arrowhead)

Table 5 Correlations between infarct volume and histopathologic plaque characteristics in patients presenting with strokes

\begin{tabular}{lrrr}
\hline & \multicolumn{3}{l}{ Infarct volume } \\
\cline { 2 - 4 } & $r$ & $r^{2}$ & $P$ \\
\hline Lumen thrombus & 0.265 & 0.070 & 0.032 \\
Plaque rupture & 0.203 & 0.041 & 0.102 \\
Lipid core & 0.051 & 0.003 & 0.684 \\
Fibrous tissue & -0.055 & 0.003 & 0.663 \\
Inflammatory cells & 0.124 & 0.015 & 0.321 \\
Foamy macrophage & 0.119 & 0.014 & 0.340 \\
Intraplaque hemorrhage & 0.035 & 0.001 & 0.783 \\
Calcification & 0.011 & $<0.001$ & 0.929 \\
Intraplaque microvessels & 0.125 & 0.016 & 0.317 \\
Overall instability & 0.106 & 0.011 & 0.398 \\
\hline
\end{tabular}

\section{Statin and lumen thrombus}

Mean lumen thrombus was significantly smaller in patients treated with statins than in untreated patients. A decrease in the incidence of venous thromboembolisms associated with statin use has been reported [32-34]. Among patients undergoing CEA, statin therapy has been correlated with a reduced plaque expression of tissue factor, tissue factor pathway inhibitor antigens and tissue factor activity [35, 36]. Statins also increase the expression of the endothelial surface anticoagulant thrombomodulin by decreasing the activation of GTPase [37] and by increasing the concentrations of endothelium-derived NO [38]. Furthermore, thrombomodulin activates the protein $\mathrm{C}$ anticoagulant system, which inactivates bound factor $\mathrm{Va}$ [39]. These mechanisms 


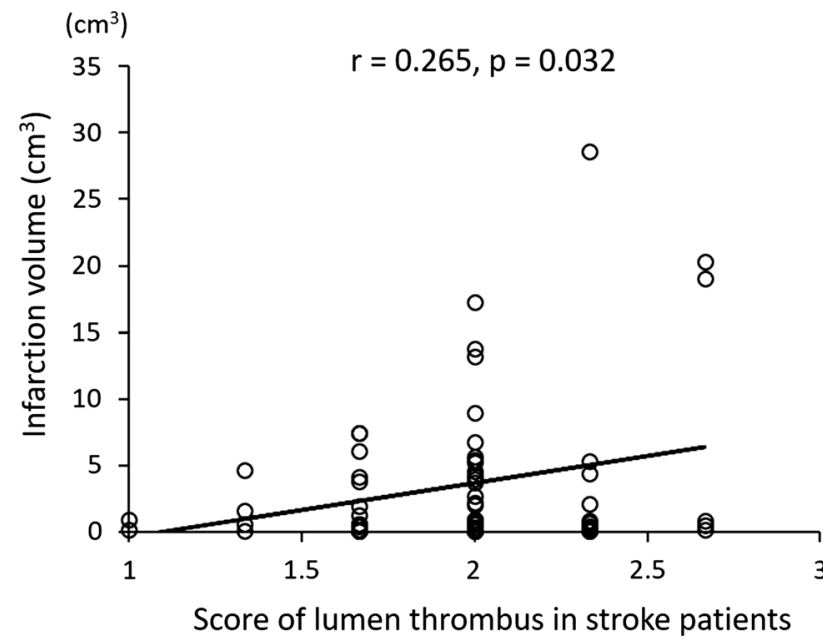

Fig. 9 Correlation between infarct volume and semi-quantitative score of lumen thrombi in 55 patients in group 1 and 11 patients in group 2, presenting with strokes. In patients presenting with strokes, the infarct volume was positively correlated to lumen thrombus $\left(r=0.265 ; r^{2}=0.070 ; P=0.032\right)$

and narrower range of plaque rupture (Fig. 6b) may decrease the size of thrombi in statin-treated patients. Since plaque rupture is a disruption of the fibrous cap with an overlying thrombus, and plaque rupture was positively correlated with intraplaque hemorrhage, one could expect a positive correlation between lumen thrombus and intraplaque hemorrhage.

\section{Statin and intraplaque microvessels}

There are at least two mechanisms that may explain the decreased intraplaque microvessels in patients treated with statins. First, the treatment was associated with significantly lower plasma concentrations of vascular endothelial growth factor [40]. Second, since inflammation is one of the strongest stimuli of vessel growth [41], less inflammation might have contributed to the formation of fewer intraplaque microvessels in patients treated with statin. A positive correlation between intraplaque microvessels and inflammatory cells was, indeed, observed in this study.

Our observations of significantly fewer intraplaque microvessels in treated than in untreated patients are concordant with a previous report [42]. Among a sample of symptomatic and asymptomatic patients who had undergone CEA, Koutouzis et al. found significantly fewer intraplaque microvessels in patients who had been, than in patients who had not been treated with statins [42].

\section{Statins and inflammation}

The inflammation score was significantly lower in patients treated with statins than in untreated patients.
Atherosclerosis is a chronic inflammatory process of the vascular wall that is initiated by excessive LDL cholesterol and is mediated by inflammatory leukocytes such as activated macrophages, neutrophils, T lymphocytes and B lymphocytes [43]. Statin therapy is associated with lower cytokine levels in carotid plaques removed at the time of CEA [44]. Statins inhibit trans-endothelial migration of leukocytes by decreasing the expression of adhesion molecules such as intercellular adhesion molecule-1, lymphocyte function-associated antigen-1 and macrophage receptor-1, which all play an important role in the adhesion and migration of leukocytes [45]. These mechanisms might all contribute to the stabilization of the carotid atherosclerotic plaques by attenuating the inflammation in patients treated with statins.

\section{Statin and infarct volume in stroke patients}

Among patients presenting with strokes whose infarct volume was $\geq 1.0 \mathrm{~cm}^{3}$, those treated with statins had significantly smaller infarcts, compared with untreated patients (Fig. 7b). Since infarct volume was positively correlated with lumen thrombus in patients who had suffered a stroke, small thrombi in the statin-treated patients might have contributed to small infarct volumes. The smaller infarct volumes observed in patients treated with statins are also explained by earlier studies. One of the putative pleiotropic effects of statins is their effect on endothelial NO synthase, which, when absent in mice, is associated with larger infarcts size [46]. The effects of statins are likely mediated by Rho/Rho kinase since Rho kinase inhibitors upregulate endothelial NO synthase and increase the cerebral blood flow in mice [47].

Smaller infarct volumes in statin-treated patients might be associated with more favorable clinical outcomes. In other studies, the prescription of statin before the onset of strokes increased the survival at 7,90 days and 1 year [48], as well as improved the functional outcome at 90 days [49].

\section{Non-significant pathological indices in comparative analysis}

Statistically non-significant changes in plaque characteristics such as lipid core, fibrous tissue, calcifications and overall instability might be explained by too short an exposure to statins for these treatment effects to develop, as suggested by a previous experimental study [50]. Insignificant differences regarding foamy macrophages might be due to the nearly 50 days, on average, between onset of stroke and CEA, or to our choice of an imperfect methodology. 


\section{Limitations of our study}

The sample size of this retrospective, observational study, conducted at three medical centers, was small. Its results need to be confirmed by a study including a larger number of patients. Second, the type, dose and duration of statin administration was variable. Third, the patients included in our study underwent CEA after a relatively long median time interval after the stroke, while current professional practice guidelines recommend that patients presenting with symptomatic carotid stenoses undergo CEA within 14 days of the latest event. Therefore, further histopathological analyses may reveal a significantly less prominent infiltration by foamy macrophages in patients previously treated with statins. Fourth, we did not measure other biomarkers such as high-sensitivity C-reactive protein, which is associated with the risk of ischemic stroke and vascular events [51].

\section{Conclusion}

This clinico-pathological analysis suggests that statin therapy stabilizes the carotid atherosclerotic plaques, which, in symptomatic patients undergoing CEA, may decrease the volume of infarcts. This stabilization of the plaques might be a pleiotropic effect, besides the lowering of lipids conferred by statins.

Acknowledgements We thank Ms. Tomoko Takenami for her contributions in the immunohistological staining. Rodolphe Ruffy, MD, http://www.cardioscript.com, reviewed our manuscript for style and language.

\section{Compliance with ethical standards}

Conflict of interest The authors have no potential conflict of interest to disclose.

Open Access This article is distributed under the terms of the Creative Commons Attribution 4.0 International License (http://creativeco mmons.org/licenses/by/4.0/), which permits unrestricted use, distribution, and reproduction in any medium, provided you give appropriate credit to the original author(s) and the source, provide a link to the Creative Commons license, and indicate if changes were made.

\section{References}

1. Balk EM, Karas RH, Jordan HS, Kupelnick B, Chew P, Lau J (2004) Effects of statins on vascular structure and function: a systematic review. Am J Med 117:775-790

2. Amarenco P, Bogousslavsky J, Callahan A 3rd, Goldstein LB, Hennerici M, Rudolph AE, Sillesen H, Simunovic L, Szarek M, Welch KM, Zivin JA, Stroke Prevention by Aggressive Reduction in Cholesterol Levels I (2006) High-dose atorvastatin after stroke or transient ischemic attack. N Engl J Med 355:549-559

3. Cholesterol Treatment Trialists C, Baigent C, Blackwell L, Emberson J, Holland LE, Reith C, Bhala N, Peto R, Barnes EH, Keech A, Simes J, Collins R (2010) Efficacy and safety of more intensive lowering of LDL cholesterol: a meta-analysis of data from 170,000 participants in 26 randomised trials. Lancet 376:1670-1681

4. Bustos C, Hernandez-Presa MA, Ortego M, Tunon J, Ortega L, Perez F, Diaz C, Hernandez G, Egido J (1998) HMG-CoA reductase inhibition by atorvastatin reduces neointimal inflammation in a rabbit model of atherosclerosis. J Am Coll Cardiol 32:2057-2064

5. Bartoli M, Al-Shabrawey M, Labazi M, Behzadian MA, Istanboli M, El-Remessy AB, Caldwell RW, Marcus DM, Caldwell RB (2009) HMG-CoA reductase inhibitors (statin) prevents retinal neovascularization in a model of oxygen-induced retinopathy. Invest Ophthalmol Vis Sci 50:4934-4940

6. Furberg CD, Adams HP Jr, Applegate WB, Byington RP, Espeland MA, Hartwell T, Hunninghake DB, Lefkowitz DS, Probstfield J, Riley WA, Young B (1994) Effect of lovastatin on early carotid atherosclerosis and cardiovascular events. Asymptomatic Carotid Artery Progression Study (ACAPS) Research Group. Circulation 90:1679-1687

7. Amarenco P, Labreuche J, Lavallee P, Touboul PJ (2004) Statins in stroke prevention and carotid atherosclerosis: systematic review and up-to-date meta-analysis. Stroke 35:2902-2909

8. Watanabe K, Sugiyama S, Kugiyama K, Honda O, Fukushima H, Koga H, Horibata Y, Hirai T, Sakamoto T, Yoshimura M, Yamashita Y, Ogawa H (2005) Stabilization of carotid atheroma assessed by quantitative ultrasound analysis in nonhypercholesterolemic patients with coronary artery disease. J Am Coll Cardiol 46:2022-2030

9. Tawakol A, Fayad ZA, Mogg R, Alon A, Klimas MT, Dansky H, Subramanian SS, Abdelbaky A, Rudd JH, Farkouh ME, Nunes IO, Beals CR, Shankar SS (2013) Intensification of statin therapy results in a rapid reduction in atherosclerotic inflammation: results of a multicenter fluorodeoxyglucose-positron emission tomography/computed tomography feasibility study. J Am Coll Cardiol 62:909-917

10. Ibrahimi P, Jashari F, Bajraktari G, Wester P, Henein MY (2015) Ultrasound assessment of carotid plaque echogenicity response to statin therapy: a systematic review and meta-analysis. Int $\mathrm{J}$ Mol Sci 16:10734-10747

11. Virmani R, Kolodgie FD, Burke AP, Farb A, Schwartz SM (2000) Lessons from sudden coronary death: a comprehensive morphological classification scheme for atherosclerotic lesions. Arterioscler Thromb Vasc Biol 20:1262-1275

12. Redgrave JN, Gallagher P, Lovett JK, Rothwell PM (2008) Critical cap thickness and rupture in symptomatic carotid plaques: the oxford plaque study. Stroke 39:1722-1729

13. Lovett JK, Gallagher PJ, Hands LJ, Walton J, Rothwell PM (2004) Histological correlates of carotid plaque surface morphology on lumen contrast imaging. Circulation 110:2190-2197

14. Redgrave JN, Lovett JK, Gallagher PJ, Rothwell PM (2006) Histological assessment of 526 symptomatic carotid plaques in relation to the nature and timing of ischemic symptoms: the Oxford plaque study. Circulation 113:2320-2328

15. Howard DP, van Lammeren GW, Redgrave JN, Moll FL, de Vries JP, de Kleijn DP, de Borst GJ, Pasterkamp G, Rothwell PM (2013) Histological features of carotid plaque in patients with ocular ischemia versus cerebral events. Stroke 44:734-739

16. Howard DP, van Lammeren GW, Rothwell PM, Redgrave JN, Moll FL, de Vries JP, de Kleijn DP, den Ruijter HM, de Borst GJ, Pasterkamp G (2015) Symptomatic carotid atherosclerotic 
disease: correlations between plaque composition and ipsilateral stroke risk. Stroke 46:182-189

17. Broderick JP, Brott TG, Duldner JE, Tomsick T, Huster G (1993) Volume of intracerebral hemorrhage. A powerful and easy-to-use predictor of 30-day mortality. Stroke 24:987-993

18. Gossl M, Yoon MH, Choi BJ, Rihal C, Tilford JM, Reriani M, Gulati R, Sandhu G, Eeckhout E, Lennon R, Lerman LO, Lerman A (2014) Accelerated coronary plaque progression and endothelial dysfunction: serial volumetric evaluation by IVUS. JACC Cardiovasc Imaging 7:103-104

19. Lerman A, Zeiher AM (2005) Endothelial function: cardiac events. Circulation 111:363-368

20. Anderson TJ, Meredith IT, Yeung AC, Frei B, Selwyn AP, Ganz P (1995) The effect of cholesterol-lowering and antioxidant therapy on endothelium-dependent coronary vasomotion. N Engl J Med 332:488-493

21. Vita JA, Yeung AC, Winniford M, Hodgson JM, Treasure CB, Klein JL, Werns S, Kern M, Plotkin D, Shih WJ, Mitchel Y, Ganz P (2000) Effect of cholesterol-lowering therapy on coronary endothelial vasomotor function in patients with coronary artery disease. Circulation 102:846-851

22. Beckman JA, Liao JK, Hurley S, Garrett LA, Chui D, Mitra D, Creager MA (2004) Atorvastatin restores endothelial function in normocholesterolemic smokers independent of changes in low-density lipoprotein. Circ Res 95:217-223

23. Laufs U, La Fata V, Plutzky J, Liao JK (1998) Upregulation of endothelial nitric oxide synthase by $\mathrm{HMG} \mathrm{CoA}$ reductase inhibitors. Circulation 97:1129-1135

24. Gonzalez-Fernandez F, Jimenez A, Lopez-Blaya A, Velasco S, Arriero MM, Celdran A, Rico L, Farre J, Casado S, LopezFarre A (2001) Cerivastatin prevents tumor necrosis factoralpha-induced downregulation of endothelial nitric oxide synthase: role of endothelial cytosolic proteins. Atherosclerosis 155:61-70

25. Nakamura T, Ushiyama C, Hirokawa K, Osada S, Shimada N, Koide H (2001) Effect of cerivastatin on urinary albumin excretion and plasma endothelin- 1 concentrations in type 2 diabetes patients with microalbuminuria and dyslipidemia. Am J Nephrol 21:449-454

26. Daemen MJ, Ferguson MS, Gijsen FJ, Hippe DS, Kooi ME, Demarco K, van der Wal AC, Yuan C, Hatsukami TS (2016) Carotid plaque fissure: An underestimated source of intraplaque hemorrhage. Atherosclerosis 254:102-108

27. Konishi T, Funayama N, Yamamoto T, Morita T, Hotta D, Nomura R, Nakagaki Y, Murahashi T, Kamiyama K, Yoshimoto T, Aoki T, Nishihara H, Tanaka S (2017) Pathological quantification of carotid artery plaque instability in patients undergoing carotid endarterectomy. Circ J 82:258-266

28. Michel JB, Virmani R, Arbustini E, Pasterkamp G (2011) Intraplaque haemorrhages as the trigger of plaque vulnerability. Eur Heart J 32:1977-1985, 1985a, 1985b, 1985c

29. Jeney V, Balla G, Balla J (2014) Red blood cell, hemoglobin and heme in the progression of atherosclerosis. Front Physiol 5:379

30. Kolodgie FD, Gold HK, Burke AP, Fowler DR, Kruth HS, Weber DK, Farb A, Guerrero LJ, Hayase M, Kutys R, Narula J, Finn AV, Virmani R (2003) Intraplaque hemorrhage and progression of coronary atheroma. N Engl J Med 349:2316-2325

31. Virmani R, Kolodgie FD, Burke AP, Finn AV, Gold HK, Tulenko TN, Wrenn SP, Narula J (2005) Atherosclerotic plaque progression and vulnerability to rupture: angiogenesis as a source of intraplaque hemorrhage. Arterioscler Thromb Vasc Biol 25:2054-2061

32. Smith NL, Harrington LB, Blondon M, Wiggins KL, Floyd JS, Sitlani CM, McKnight B, Larson EB, Rosendaal FR, Heckbert SR, Psaty BM (2016) The association of statin therapy with the risk of recurrent venous thrombosis. J Thromb Haemost 14:1384-1392

33. Kunutsor SK, Seidu S, Khunti K (2017) Statins and primary prevention of venous thromboembolism: a systematic review and meta-analysis. Lancet Haematol 4:e83-e93

34. Glynn RJ, Danielson E, Fonseca FA, Genest J, Gotto AM Jr, Kastelein JJ, Koenig W, Libby P, Lorenzatti AJ, MacFadyen JG, Nordestgaard BG, Shepherd J, Willerson JT, Ridker PM (2009) A randomized trial of rosuvastatin in the prevention of venous thromboembolism. N Engl J Med 360:1851-1861

35. Cortellaro M, Cofrancesco E, Arbustini E, Rossi F, Negri A, Tremoli E, Gabrielli L, Camera M (2002) Atorvastatin and thrombogenicity of the carotid atherosclerotic plaque: the ATROCAP study. Thromb Haemost 88:41-47

36. Eto M, Kozai T, Cosentino F, Joch H, Luscher TF (2002) Statin prevents tissue factor expression in human endothelial cells: role of Rho/Rho-kinase and Akt pathways. Circulation 105:1756-1759

37. Masamura K, Oida K, Kanehara H, Suzuki J, Horie S, Ishii H, Miyamori I (2003) Pitavastatin-induced thrombomodulin expression by endothelial cells acts via inhibition of small $\mathrm{G}$ proteins of the Rho family. Arterioscler Thromb Vasc Biol 23:512-517

38. McLean DL, Kim J, Kang Y, Shi H, Atkins GB, Jain MK, Chun HJ (2012) Apelin/APJ signaling is a critical regulator of statin effects in vascular endothelial cells-brief report. Arterioscler Thromb Vasc Biol 32:2640-2643

39. Undas A, Brummel KE, Musial J, Mann KG, Szczeklik A (2001) Simvastatin depresses blood clotting by inhibiting activation of prothrombin, factor V, and factor XIII and by enhancing factor Va inactivation. Circulation 103:2248-2253

40. Sahebkar A, Ponziani MC, Goitre I, Bo S (2015) Does statin therapy reduce plasma VEGF levels in humans? A systematic review and meta-analysis of randomized controlled trials. Metabolism 64:1466-1476

41. Silvestre JS, Mallat Z, Tedgui A, Levy BI (2008) Post-ischaemic neovascularization and inflammation. Cardiovasc Res 78:242-249

42. Koutouzis M, Nomikos A, Nikolidakis S, Tzavara V, Andrikopoulos V, Nikolaou N, Barbatis C, Kyriakides ZS (2007) Statin treated patients have reduced intraplaque angiogenesis in carotid endarterectomy specimens. Atherosclerosis 192:457-463

43. Libby P, Tabas I, Fredman G, Fisher EA (2014) Inflammation and its resolution as determinants of acute coronary syndromes. Circ Res 114:1867-1879

44. Molloy KJ, Thompson MM, Schwalbe EC, Bell PR, Naylor AR, Loftus IM (2004) Comparison of levels of matrix metalloproteinases, tissue inhibitor of metalloproteinases, interleukins, and tissue necrosis factor in carotid endarterectomy specimens from patients on versus not on statins preoperatively. Am J Cardiol 94:144-146

45. Schonbeck U, Libby P (2004) Inflammation, immunity, and HMG-CoA reductase inhibitors: statins as antiinflammatory agents? Circulation 109:II18-II26

46. Laufs U, Fata VL, Liao JK (1997) Inhibition of 3-hydroxy3-methylglutaryl (HMG)-CoA reductase blocks hypoxia-mediated down-regulation of endothelial nitric oxide synthase. J Biol Chem 272:31725-31729

47. Rikitake Y, Kim HH, Huang Z, Seto M, Yano K, Asano T, Moskowitz MA, Liao JK (2005) Inhibition of Rho kinase (ROCK) leads to increased cerebral blood flow and stroke protection. Stroke 36:2251-2257

48. Ni Chroinin D, Callaly EL, Duggan J, Merwick A, Hannon N, Sheehan O, Marnane M, Horgan G, Williams EB, Harris D, Kyne L, McCormack PM, Moroney J, Grant T, Williams D, Daly L, Kelly PJ (2011) Association between acute 
statin therapy, survival, and improved functional outcome after ischemic stroke: the North Dublin Population Stroke Study. Stroke 42:1021-1029

49. Ni Chroinin D, Asplund K, Asberg S, Callaly E, CuadradoGodia E, Diez-Tejedor E, Di Napoli M, Engelter ST, Furie KL, Giannopoulos S, Gotto AM Jr, Hannon N, Jonsson F, Kapral MK, Marti-Fabregas J, Martinez-Sanchez P, Milionis HJ, Montaner J, Muscari A, Pikija S, Probstfield J, Rost NS, Thrift AG, Vemmos K, Kelly PJ (2013) Statin therapy and outcome after ischemic stroke: systematic review and meta-analysis of observational studies and randomized trials. Stroke 44:448-456
50. Aikawa M, Rabkin E, Okada Y, Voglic SJ, Clinton SK, Brinckerhoff CE, Sukhova GK, Libby P (1998) Lipid lowering by diet reduces matrix metalloproteinase activity and increases collagen content of rabbit atheroma: a potential mechanism of lesion stabilization. Circulation 97:2433-2444

51. Kitagawa K, Hosomi N, Nagai Y, Kagimura T, Ohtsuki T, Origasa $\mathrm{H}$, Minematsu K, Uchiyama S, Nakamura M, Matsumoto M, Investigators JS (2017) Reduction in high-sensitivity C-reactive protein levels in patients with ischemic stroke by statin treatment: Hs-CRP sub-study in J-STARS. J Atheroscler Thromb 24:1039-1047 